\title{
Investigation of a Distance Presentation Method using Speech Audio Navigation for the Blind or Visually Impaired
}

\author{
Chikamune Wada \\ Graduate School of Life Science and Systems Engineering, Kyushu Institute of Technology \\ Japan
}

\section{Introduction}

Many navigation devices for blind or visually impaired individuals have been developed (There is a lot of researches. For example, Johnson, 2006, Velazquez, 2006). The creation of these devices requires the management of three critical research elements: first, detecting obstacles; second, measuring the present location of the blind or impaired individual for route navigation; third, method of informing the individual of direction and distance.

Regarding obstacle detection, we expect this activity to be performed using robot technology for autonomous transfer.

As for location measurement, recent studies indicate location can be determined via GPS (Global Positioning Satellite) or RFID (Radio Frequency Identification) to guide the blind or impaired person (Miyanaga, 2008, Jongwhoa, 2006, Ding, 2007). However, GPS cannot be used in underground locations or urban areas surrounded by tall buildings because of poor signal detection. In addition, many ID chips must be buried under the roads to allow the use of RFID so that location measurement using RFID is likely to be limited. To avoid these difficulties, we proposed a measurement method based on foot movement. We will detail this measurement method further in this article.

Concerning the method of presenting information to the blind and visually impaired, we believe that the device should provide the individual with necessary information about the direction and distance of obstacles/destinations. Judging from the natural human reaction to sound sources, we hypothesized that humans grasp direction based on the position of the head. Consequently, we proposed a head-centered direction display method. Our previous experimental results show that human beings can comprehend directions simply based on head position (Asonuma, Matsumoto \& Wada, 2005). Incidentally, other similar systems currently use speech audio to allow the blind or impaired person to determine distance, yet difficulty still exists for the individual to accurately assess distances from speech audio. For example, this type of system notifies the person that he or she must turn right 3 meters in front of him or her if he or she wants to arrive at an entrance. However, the impaired individual may not be able to imagine a distance of 3 meters due to lack of prior physical reference. Even though there are difficulties in assessing distance using speech audio, it is thought to be a better presentation method than a tactile sensation such as vibration, at least from the standpoint of training necessity. Thus, we are attempting to examine the optimal 
presentation method when speech audio is used. We investigated which speech expressions of distance were most appropriate to assess distance easily and selected the three expressions: length, number of steps and time because individuals used these expressions routinely.

To correctly utilize these three expressions, a subject's stride and position had to be accurately measured, so we developed a stride measurement device. First, we will introduce the distance measurement method based on foot movement. Then, we will explain the distance presentation method using speech audio in conjunction with our stride measurement device.

\section{Distance measurement method based on foot movement}

\subsection{System setup}

Figure 1 represents a schematic figure of our stride measurement device. During the swing phase, the foot position is calculated from the combined data of acceleration sensors and gyro sensors. To reduce error using integral calculus, the distance between both feet is measured with ultrasonic sensors during the double supporting stance phase. Pressure sensors on both the heel and toe were employed to help decide whether it was a double supporting stance phase or not. Using this measurement method, the measurement error will not increase, though the walking distance will, and foot position will be measured with no limitation of the measurement area.

To complete the measurement device, we investigated a situation using an optimal arrangement of acceleration and ultrasonic sensors, which had been placed on the foot.

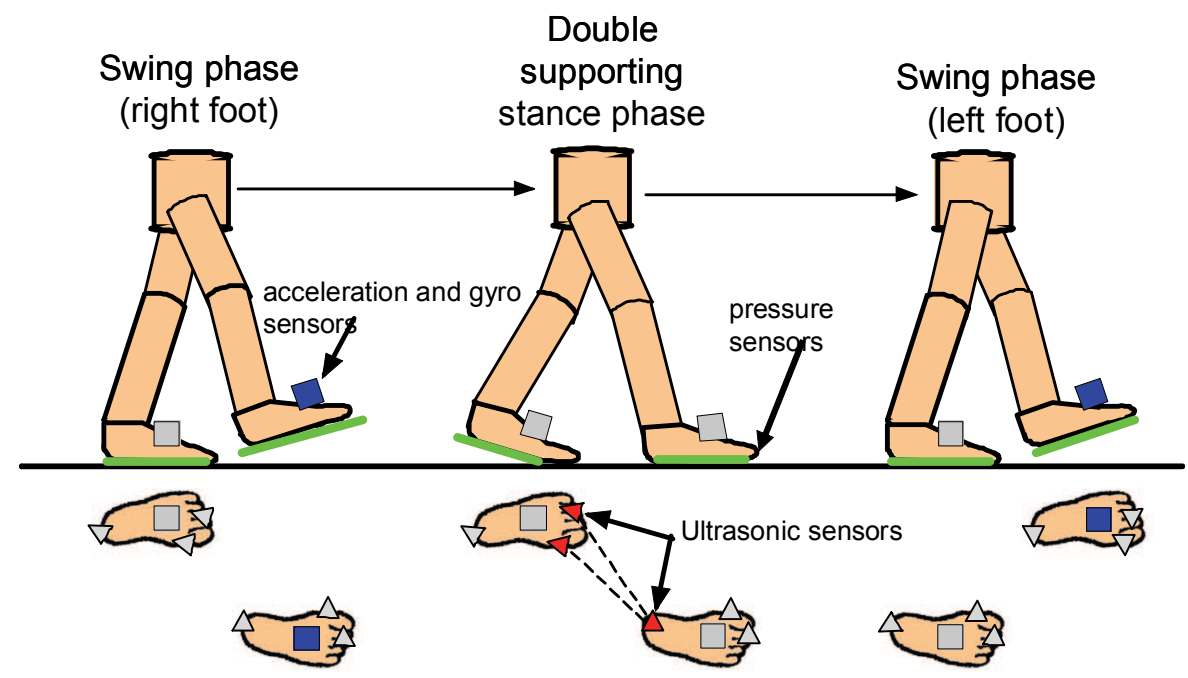

Figure 1. Stride measurement device

(a) Attaching the acceleration sensors.

First, we measured the maximum acceleration of the foot while walking to determine the necessary measurement range of the acceleration sensor. The accelerations of seven points of 
the foot (shown in Fig. 2) were measured with a motion capture system. The subjects were 10 young people, who were asked to walk for 10 steps and repeated the exercise three times. The theoretical maximum measurement error was $1 \mathrm{~cm}$ in this motion capture system. Table 1 shows the maximum and average accelerations. Data from Table 1 shows maximum acceleration was under 10G, so we decided to use an acceleration sensor that could measure up to $10 \mathrm{G}$.

Next, we attempted to determine the optimal position to measure the value of the acceleration sensor. We created a measurement system consisting of a triple-axis acceleration sensor with a triple-axis gyro sensor and placed them on the seven points of the foot (shown in Fig. 2). Three subjects were then asked to walk 10 steps for 10 trials. During the experiment, the walking distance was calculated with our measurement system as well as by the motion capture system. After completion of the measurement, a distance error was established. From our results, the average distance error per step was approximately $1 \mathrm{~cm}$ for all points of the foot. Therefore, we concluded that the acceleration sensor should be attached to the heel.

\section{$\underline{\text { Rlght foot }}$}
1. Heel
2. First toe
5. Inner ankle
3. Little toe
6. Outer ankle
4. Big toe
7. Instep

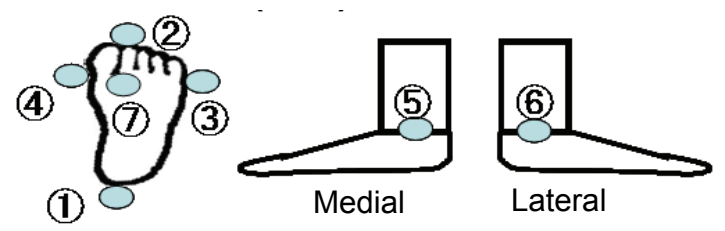

Figure 2. Acceleration measurement points

\begin{tabular}{|c|c|c|c|c|c|c|c|c|}
\hline Inner ankle & & & Outer ank & & & Instep & & \\
\hline Lateral & Forward & Upward & Lateral & Forward & Upward & Lateral & Forward & Upward \\
\hline 5.87 & 9.5 & 6.54 & 4.18 & $3 \quad 9.3$ & \begin{tabular}{|l|l|}
5.28 \\
\end{tabular} & 34.26 & 7.75 & \\
\hline 48.2 & 85.4 & 75.7 & 40.6 & 89.1 & 55.1 & 49 & 92.1 & \\
\hline
\end{tabular}

Table 1. Acceleration measurement points $\left(\left[\mathrm{m} / \mathrm{s}^{2}\right]\right)$

(b) Attaching the ultrasonic sensors.

To accurately measure the distance between both feet, it was critical where we placed the ultrasonic sensors, so we simulated the sensor arrangement. As exhibited in Fig. 3, we explored which arrangement was measured correctly when the sensor position varied. Guided by our experiment results, the sensor position was chosen as shown in Fig. 4. One transmitter of the ultrasonic sensor was put on the heel and two receivers were placed on the toe. Two of the receivers were then rotated at 60 and 70 degrees toward the frontal direction of foot. Using this arrangement, the distance between both feet could be calculated correctly as the normal walking pattern of a non-disabled adult. 


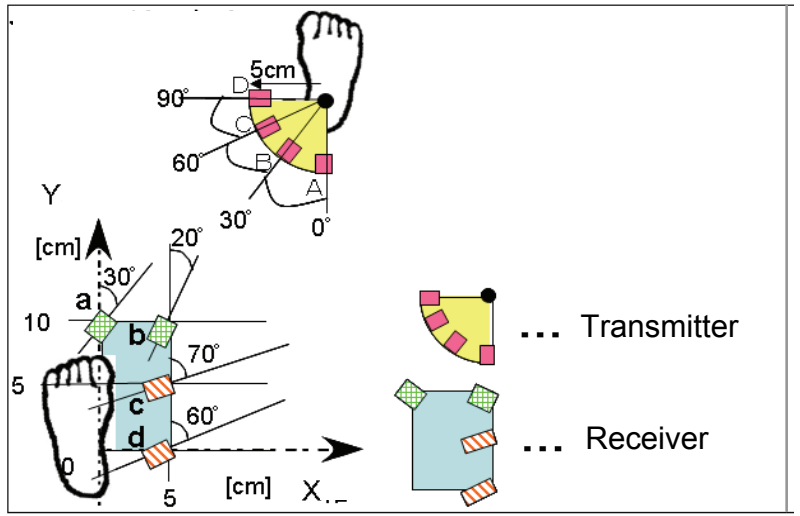

Figure 3. Ultrasonic sensor arrangement to decide optimal sensor position

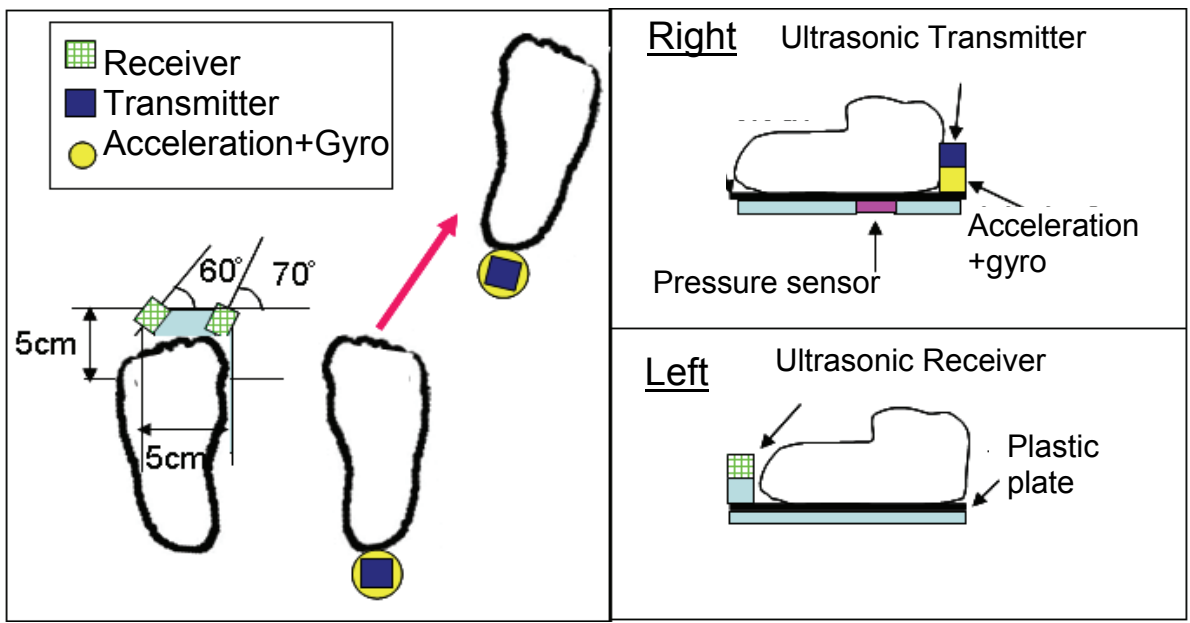

Figure 4. . Stride measurement device (sensor arrangement was shown)

Combining two triple-axis acceleration sensors, two triple-axis gyro sensors, six ultrasonic sensors and twenty-four pressure sensors, we constructed a stride measurement device (shown in Fig. 4).

\subsection{System Evaluation}

The subject was asked to walk while wearing our stride measurement device to evaluate its accuracy. The movements of the feet were also measured using the motion capture system and the accuracy was calculated. Three subjects walked for 10 steps and repeated this exercise for 10 trials.

Figure 5 shows a sample result of a subject during the swing phase. This figure depicts the tracks of the heel. The upper left image illustrates the tracks in a lateral direction, whereas the upper right shows the forward direction and the lower left displays the upward 
direction. A solid line represents the results of our device while a dotted line reveals the results of the motion capture system. According to this figure, our measurement system closely measured the track of the foot. The maximum errors for all trials were 2.8, 3.1 and 2.5 $\mathrm{cm}$ in the lateral, forward and upward directions, respectively.

The average errors in the walking phase varied from the swing phase to the double supporting stance phase and were 1.5 and $1.9 \mathrm{~cm}$ in the lateral and forward directions, respectively. These errors occurred because of the integral calculus in the calculating process of the acceleration and gyro sensors during the swing phase. However, using the measurement result of the ultrasonic sensor, those average errors decreased to 0.4 and 0.5 $\mathrm{cm}$ in the lateral and forward directions, respectively. Thus, our method measured feet movements correctly. Nevertheless, there is still an issue to be solved: Our method was used only on flat ground, that is, our method cannot be applied on stairs or steps.

Distance
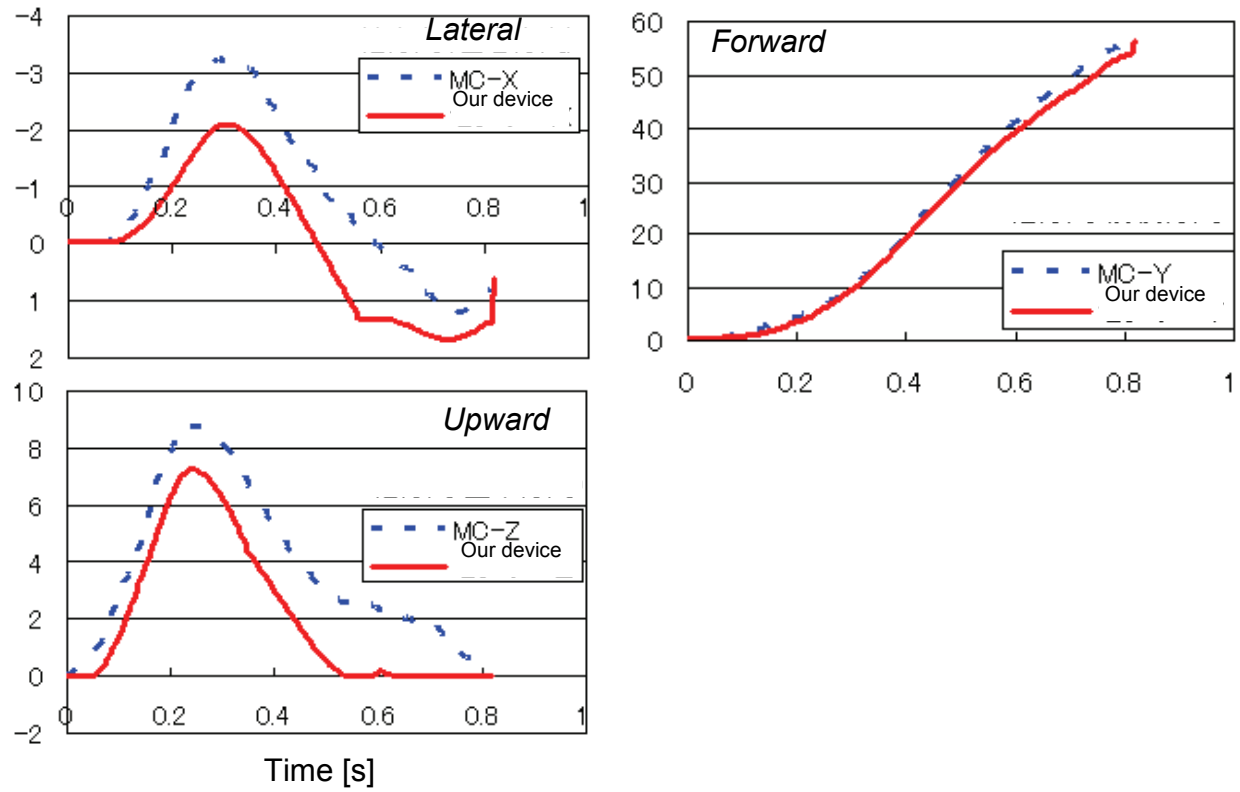

Figure 5. One result of heel tracks during swing phase

\section{Distance presentation method using speech audio}

\subsection{Experiment setup and procedure}

Next, we examined which speech expressions of distance were most appropriate in assessing distance easily. As mentioned above, we selected the three expressions: length, number of steps and time.

[Length]: When a speech expression is " 3 meters" for example, the expression indicates an obstacle is 3 meters in front of the subject. Prepared expressions were $1 \mathrm{~m}, 2 \mathrm{~m}, 3 \mathrm{~m}, 4 \mathrm{~m}$ and $5 \mathrm{~m}$ for this experiment. 
[Number of steps]: When a speech expression is "3 steps" for instance, the expression signifies the individual will hit an obstacle after three steps walking at the present stride. In this case, prepared expressions were 1 step, 2 steps, 3 steps, 4 steps and 5 steps.

[Time]: When a speech expression is " 3 seconds" for example, the expression means the subject will hit an obstacle after three seconds of walking at the present speed, and prepared expressions were 1 second, 2 seconds, 3 seconds, 4 seconds and 5 seconds.

Figure 6 illustrates our experimental procedure. In the experiment, the subjects wore eyeshades as well as our stride measurement devices. The subjects were asked to walk toward an obstacle that was represented by a $2 \mathrm{~m}$ high board. When the subjects arrived at a specific point, one of the three types of expressions were presented through a speaker situated behind the subjects. After hearing the expression, the subjects were asked to obey it and perform the necessary action. For instance, if the subjects heard " $3 \mathrm{~m}$ ", they should walk as long as they felt the distance was $3 \mathrm{~m}$, and if they collided with the obstacle before they intended to stop, the trial was at an end. If they did not hit the obstacle after they obeyed the expression, the distance between the subject and the obstacle was measured and the individual was asked to walk further until he or she collided with the obstacle. After the trials, the subjects were asked to indicate their sensory feeling of security at five steps using the SD method. Five non-visually disabled subjects participated in this experiment, and 10 trials were completed for each expression.

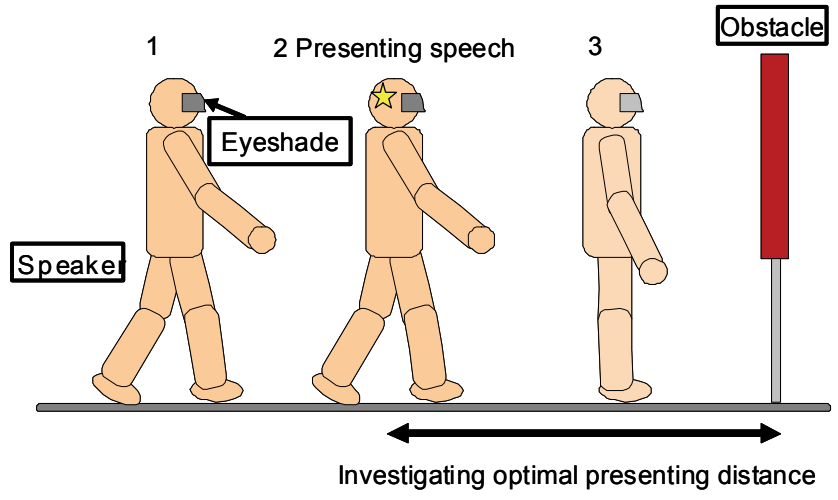

Figure 6. Experiment setup

\subsection{Experiment results and discussion}

Figure 7 shows our experiment results. The dark gray bar, white bar and light gray bar indicate the results of "length," "steps" and "time" expressions, respectively. The vertical axis indicates the sensory feeling of security at five steps, and value 5 shows when the subjects felt most relieved. The horizontal axis illustrates the length in meters, the number of steps and time in seconds.

As seen in this figure, relatively high evaluation score results were obtained when the expressions were $3 \mathrm{~m}, 3$ steps, 3 seconds, 4 steps and 4 seconds. Furthermore, Table 2 exhibits the bumping rate of a subject into an obstacle, and according to this table, relatively low bumping rates were obtained when the expressions were 2 steps, $3 \mathrm{~m}, 3$ steps, 3 seconds and 4 seconds. 
From the data supplied by the bumping rate, the expression "2 steps" was optimal. However, the subjective evaluation was not as beneficial. The subjects suddenly almost stopped walking when they heard "2 steps." Then, they did not bump into the obstacle. Nevertheless, they concentrated well enough to hear the expression to stop because actually there was not enough distance margin to complete a stop action.

When expressions were "length" and "time," the bumping rates were neither substandard nor improved. Expressions of "length" and "time" were easy to comprehend, but there was a variation in subjective length and subjective time. Then, the bumping rates for "length and time" did not decrease.

From the data mentioned above, we considered the expression " 3 steps" optimal to present distance in order to avoid bumping into the obstacle.

Subjective evaluation

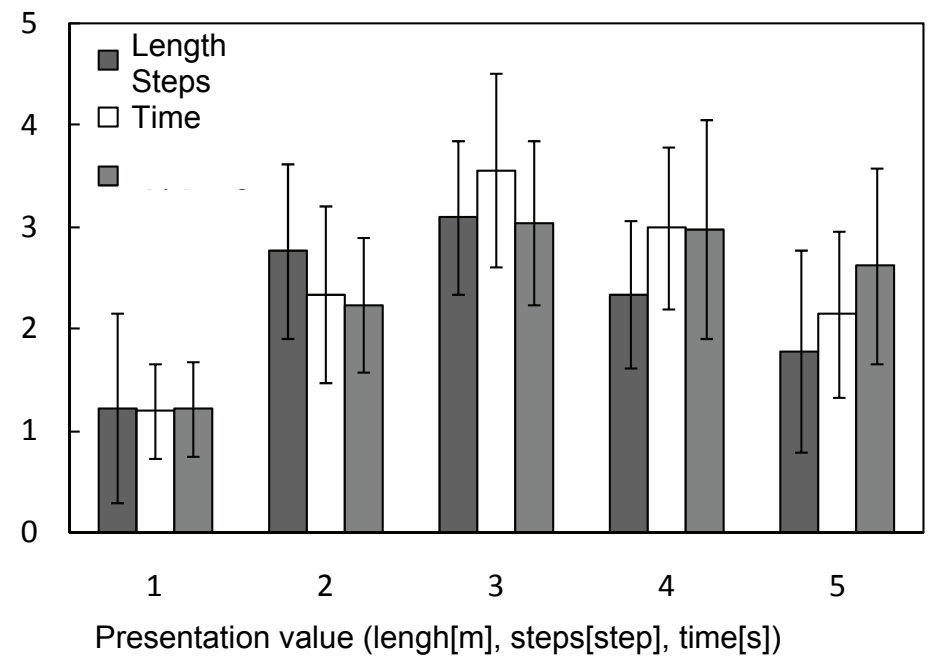

Figure 7. Experiment results

\begin{tabular}{|l|r|r|r|r|r|}
\hline & $1[\mathrm{~m}, \mathrm{steps}, \mathrm{s}]$ & $2[\mathrm{~m}, \mathrm{steps}, \mathrm{s}]$ & $3[\mathrm{~m}, \mathrm{steps}, \mathrm{s}]$ & $4[\mathrm{~m}, \mathrm{steps}, \mathrm{s}]$ & $5[\mathrm{~m}, \mathrm{steps}, \mathrm{s}]$ \\
\hline Length & $50 \%$ & $10 \%$ & $6 \%$ & $14 \%$ & $20 \%$ \\
\hline $\begin{array}{l}\text { Number of } \\
\text { steps }\end{array}$ & $28 \%$ & $4 \%$ & $2 \%$ & $12 \%$ & $24 \%$ \\
\hline Time & $36 \%$ & $14 \%$ & $8 \%$ & $8 \%$ & $10 \%$ \\
\hline
\end{tabular}

Table 2. Bumping rates

\section{Conclusions and continuing research}

In this article, we introduced a distance presentation method using speech audio. Although the experiment was conducted within a short walking distance inside a laboratory, we 
demonstrated that the expression " $3 \mathrm{~m}$ " was the optimal presentation method to avoid an obstacle with a sensory feeling of security.

During this experiment, our stride measurement device was connected to a computer with a wire; therefore, we were unable to execute experiments for longer walking distances. As a result, we are constructing wireless stride measurement devices. Combining our new stride measurement device, our distance presentation method, our direction display method and our obstacle detection technique, we will create an obstacle avoidance system and demonstrate the efficiency of our system in an open air environment.

\section{References}

Asonuma, M., Matsumoto, M. \& Wada, C. (2005). Study on the use Air Stimulation as the Indicator in an Obstacle Avoidance System for the Visually Impaired, Proceedings of the Society of Instrument and Control Engineers annual conference 2005, MA2-14-2(CDROM), Japan, Oct 2005.

Ding, B., Yuan, H., Zang, X., \& Jiang, L. (2007). The Research on Blind Navigation System Based on RFID, Proceedings of International Conference on Wireless Communications, Networking and Mobile Computing, 2007, pp. 2058-2061, Sep 2007.

Johnson, L.A. (2006). A navigation aid for the blind using tactile-visual sensory substitution, Proceedings of Annual International Conference of the IEEE Engineering in Medicine and Biology Society, pp. 4, Aug 2006.

Jongwhoa, Na. (2006). The blind interactive guide system using RFID-based indoor positioning system, Proceedings of 10th International Conference of Computers Helping People with Special Needs, pp. 1298-1305, July 2006.

Miyanaga, Y. (2008). Promotion of Free Mobility Project, Journal of the Institute of Electrical Installation Engineers of Japan, 28, 5, pp. 320-323 (Written in Japanese)

Velazquez, R. (2006). Walking using touch: design and preliminary prototype of a noninvasive ETA for the visually impaired, Proceedings of 27th Annual International Conference of the IEEE Engineering in Medicine and Biology Society, pp. 4, Aug 2005. 


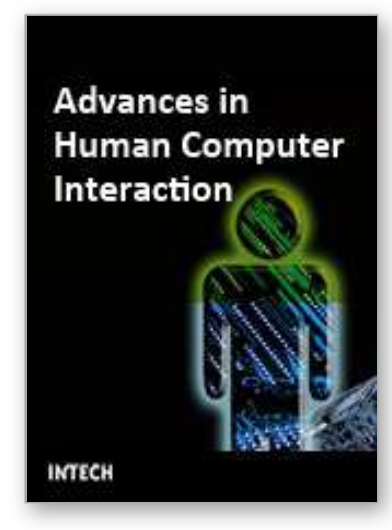

\section{Advances in Human Computer Interaction \\ Edited by Shane Pinder}

ISBN 978-953-7619-15-2

Hard cover, 600 pages

Publisher InTech

Published online 01, October, 2008

Published in print edition October, 2008

In these 34 chapters, we survey the broad disciplines that loosely inhabit the study and practice of humancomputer interaction. Our authors are passionate advocates of innovative applications, novel approaches, and modern advances in this exciting and developing field. It is our wish that the reader consider not only what our authors have written and the experimentation they have described, but also the examples they have set.

\section{How to reference}

In order to correctly reference this scholarly work, feel free to copy and paste the following:

Chikamune Wada (2008). Investigation of a Distance Presentation Method using Speech Audio Navigation for the Blind or Visually Impaired, Advances in Human Computer Interaction, Shane Pinder (Ed.), ISBN: 978-9537619-15-2, InTech, Available from:

http://www.intechopen.com/books/advances_in_human_computer_interaction/investigation_of_a_distance_pre sentation_method_using_speech_audio_navigation_for_the_blind_or_visua

\section{INTECH}

open science | open minds

\section{InTech Europe}

University Campus STeP Ri

Slavka Krautzeka 83/A

51000 Rijeka, Croatia

Phone: +385 (51) 770447

Fax: +385 (51) 686166

www.intechopen.com

\section{InTech China}

Unit 405, Office Block, Hotel Equatorial Shanghai

No.65, Yan An Road (West), Shanghai, 200040, China

中国上海市延安西路65号上海国际贵都大饭店办公楼 405 单元

Phone: +86-21-62489820

Fax: $+86-21-62489821$ 
(C) 2008 The Author(s). Licensee IntechOpen. This chapter is distributed under the terms of the Creative Commons Attribution-NonCommercialShareAlike-3.0 License, which permits use, distribution and reproduction for non-commercial purposes, provided the original is properly cited and derivative works building on this content are distributed under the same license. 